\title{
A Novel Quantitative Method for the Simultaneous Assay of Rifampicin (RIF), Isoniazid (INH), Ethambutol (EMB), and Pyrazinamide (PYP) in 4-FDC Tablets
}

\author{
MOHAMED A.M. HAGGA ${ }^{1 *}$ and SHAHEEN SULTANA ${ }^{2}$ \\ 'Department of Pharmaceutical Chemistry, Faculty of Pharmacy, \\ Northern Border University, Rafha, 91911, PO Box 840, Kingdom of Saudi Arabia. \\ ${ }^{2}$ Department of Pharmaceutics, Faculty of Pharmacy, Northern Border University, \\ Rafha, 91911, PO Box 840, Kingdom of Saudi Arabia. \\ *Corresponding author E-mail: mohamed.hagga @yahoo.com \\ http://dx.doi.org/10.13005/ojc/320629
}

(Received: October 25, 2016; Accepted: November 29, 2016)

\begin{abstract}
This paper presents the development and validation of a new ultra high performance chromatography (UHPLC) procedure for the simultaneous determination of isoniazid (INH), rifampicin (RIF), pyrazinamide (PYP), and ethambutol hydrochloride (EMB.2HCl) in four fixed-dose combination (4-FDC) anti-tubercular tablets. It is a dual wavelength single method in which, INH, RIF, and PYP were detected at $230 \mathrm{~nm}$, whereas EMB was detected at $210 \mathrm{~nm}$. The chromatographic separation was performed on Water's Acquity BEHC18 $(50 \mathrm{~mm} \times 2.1 \mathrm{~mm}, 1.7 \mu \mathrm{m}$ particle size) column at a flow rate of $0.4 \mathrm{ml} / \mathrm{min}, 40^{\circ} \mathrm{C}$ temperature, and a mobile phase consisting of triethylamine in phosphate buffer of $\mathrm{pH} 6.8,95 \%$ and acetonitrile $5 \%$. The proposed method was validated in terms of linearity, interday and intraday precision, recovery, specificity, and robustness. The results of the assay of the active constituents in two different batches of tablets were 102.3 $\pm 1.5,104.9 \pm 1.2,101.0 \pm 1.4,100.2 \pm 1.6$, and 104.8 $\pm 1.3,103.8 \pm 1.1,101.4 \pm 1.7$, and $99.9 \pm 2.1$, for INH, RIF, PYP, and EMB, respectively. The proposed method proves that the application of UHPLC technique is rewarding and additional economic benefits are gained as a result of reduction of analysis time and the consumption of the expensive HPLC grade materials.
\end{abstract}

Keywords: UHPLC, Rifampicin, Isoniazid, Pyrazinamide, Ethambutol, Simultaneous determination.

\section{INTRODUCTION}

Tuberculosis (TB) is a global infectious disease and a leading cause of death the world over. The disease afflicts about a third of the world's population, killing more than 1.3 million people annually ${ }^{1}$. Tuberculosis has a detrimental impact on the communities socially and economically and its treatment, particularly in poor and populous countries is a top priority. A major problem in the treatment of TB is the drug resistance of the pathogenic Mycobacterium tuberculosis to 
isoniazid and rifampicin ${ }^{2}$, which are the first-line drugs used as an anti-TB regimens. In 1994, to overcome drug resistance, the World Health Organization ${ }^{3}$ recommended the use of the fixeddose combination tablets of rifampicin (RIF), isoniazid (INH), pyrazinamide (PYP), and ethambutol (EMB) for TB treatment (Figure 1).

Assay of active ingredients in bulk and dosage forms is a requirement of quality control of drugs. When the dosage form contains two or more active ingredients, the analysis becomes complex and challenging. Consequently, the need for a selective, precise, accurate, analytical method is urgent. The literature reveals quantitative spectrofluorometric and voltammetric methods ${ }^{4,5}$ for the assay of RIF and INH, separately and combined in bulk, pharmaceutical formulations and human serum. Different analytical procedures for the simultaneous determination of the
4-FDC containing RIF, INH, PYP and EMB involving spectrophotometry ${ }^{6-10}$, and liquid chromatography ${ }^{11}$ 17 were reported. Recently, a review article ${ }^{18}$ summarized the latest trends in the determination of anti-tubercular drugs. The review focused on the electrochemical techniques and their inherent advantages over the other analytical procedures. Currently, 4-FDC monographs have been listed in USP34 and the International Pharmacopoeia. Both monographs quantify the 4 drugs using two lengthy HPLC systems, due to the lack of UV absorption of EMB, rendering the procedure costly and time consuming. Apart from HPLC, other methods reported for the simultaneous assay of INH, RIF, PYP and EMB are complex, lengthy and some require mathematical skill. However, HPLC is inferior in comparison to UHPLC as will be explained in the following paragraphs.<smiles>NNC(=O)c1ccncc1</smiles>

Isoniazid (INH)<smiles>NC(=O)c1cnccn1</smiles>

(PYP)<smiles>CC[C@H](CO)NCCN[C@H](CC)CO</smiles>

Ethambutol

(EMB)

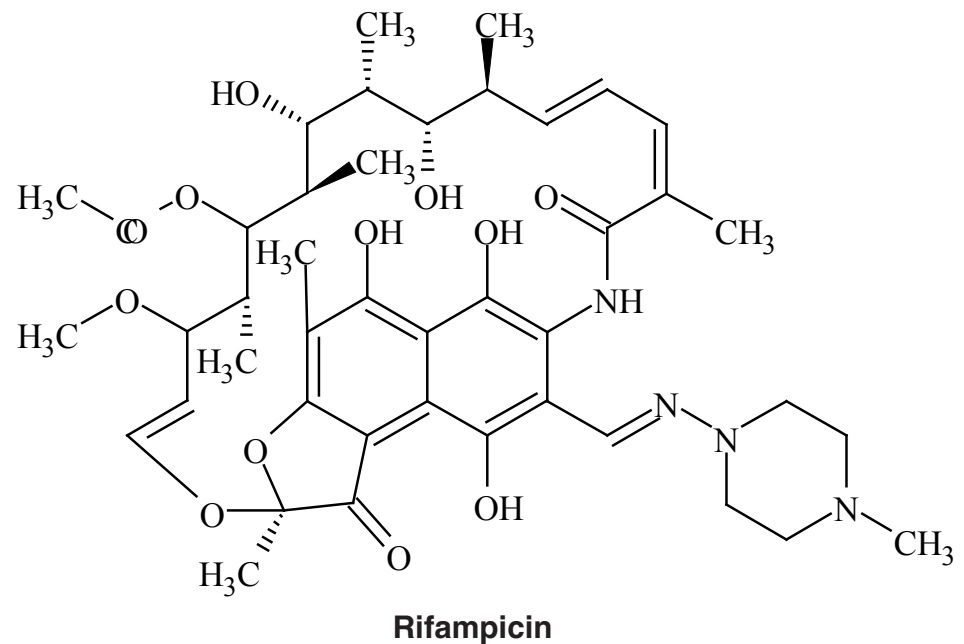

(RIF)

Fig. 1: Chemical structures of Isoniazid (INH), Pyrazinamide (PYP), Ethambutol (EMB) and Rifampicin (RIF) 
UHPLC systems were first launched by Waters in 2004. The technique is based on the same principles of HPLC, yet it possesses advanced improvement with respect to the pump, column dimensions and particle size of the stationary phase. The pump delivers typical back pressure of $15000 \mathrm{psi}$, the ID of the column is around $2 \mathrm{~mm}$ and the stationary phase particle size is less than 2 $\mu \mathrm{m}$. The improvements in instrumentation, column design, and size of stationary phase particles enable UHPLC to possess superior attributes such as speed, peak resolution, sensitivity, and less solvent consumption compared to conventional HPLC. In the present investigation, UHPLC has been applied advantageously to the simultaneous determination of INH, RIF, PYP and EMB in 4-FDC tablets. The procedure proved to be simple, precise, accurate, selective, sensitive, speedy, economical, and environment-friendly.

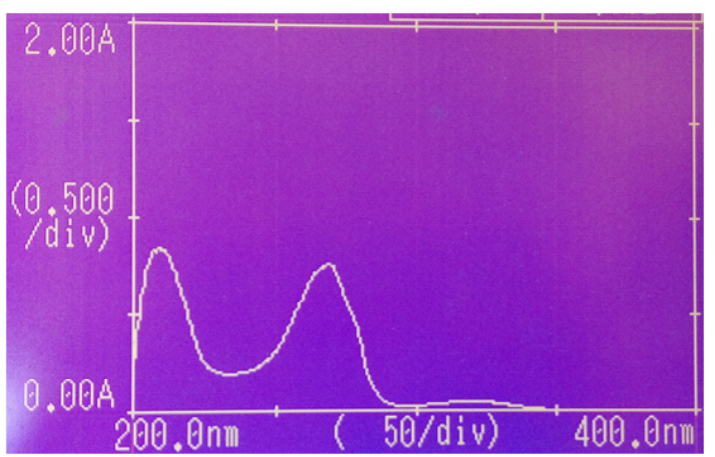

Fig. 2a: UV spectrum of Pyrazinamide $(20 \mu \mathrm{g} /$ $\mathrm{ml}$ ) in the mobile phase

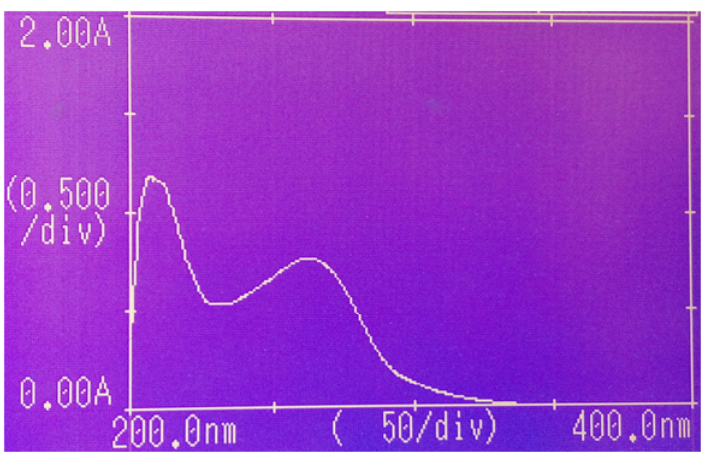

Fig. 2c: UV spectrum of Isoniazid $(25 \mu \mathrm{g} / \mathrm{ml})$ in the mobile phase

\section{MATERIALS AND METHODS}

\section{Chemicals and reagents}

RIF, INH, PYP and EMB standards were received as a gift from Arbro Pharmaceutical Ltd, New Delhi, India. HPLC-grade acetonitrile was purchased from Qualigens Fine Chemicals, Mumbai, India. Monobasic sodium phosphate, phosphoric acid, and triethylamine were purchased from Merck Ltd, Worli, Mumbai, India. Ultrapure water was produced in the laboratory by a Milli-Q purification system (Millipore, Billerica, MA, USA). Fixed dose combination tablets tested in this study were manufactured by Macleods Pharmaceuticals Ltd, Solan, India.

\section{Instrumentation}

The analysis of the 4-FDC tablets by UHPLC was performed on a Water's Acquity UHPLC system (Milford, MA, USA) equipped with an auto

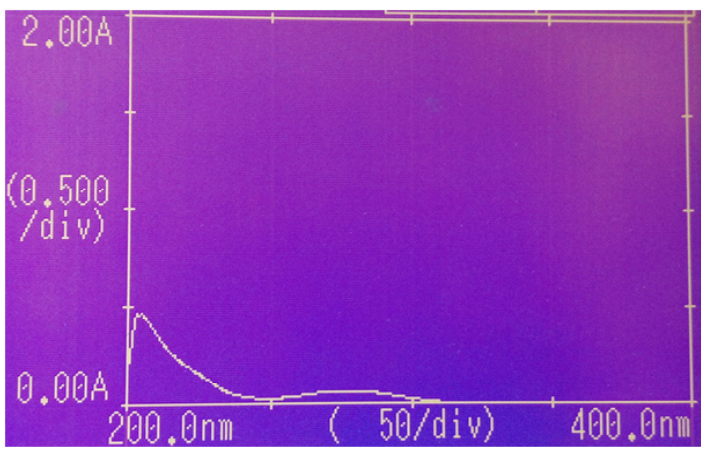

Fig. 2b: UV spectrum of Ethambutol $(400 \mu \mathrm{g} /$ $\mathrm{ml}$ ) in the mobile phase

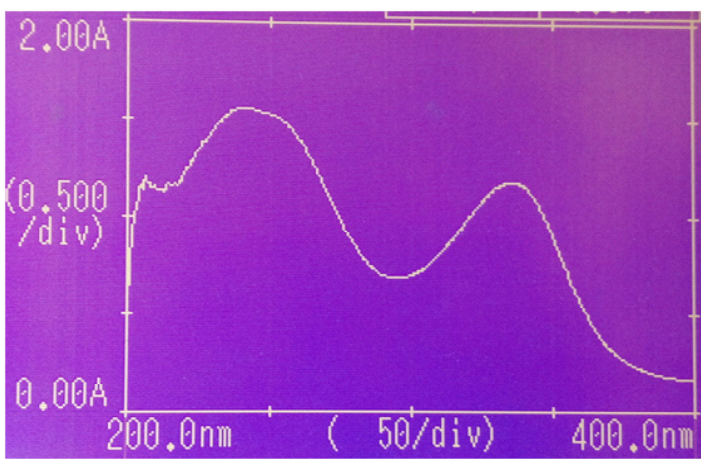

Fig. 2d: UV spectrum of Rifampicin ( $35 \mu \mathrm{g} / \mathrm{ml})$ in the mobile phase 
sampler, a binary solvent pump, a column manager composed of a column oven, a pre-column heater, and a photodiode array detector. Empower software $\mathrm{V} 1.0$ was used for data acquisition and analysis. Separations were performed on a Water's Acquity $\mathrm{BEHC}_{18}(50 \mathrm{~mm} \times 2.1 \mathrm{~mm}, 1.7 \mu \mathrm{m}$ particle size $)$, UHPLC column at $40^{\circ} \mathrm{C}$ using triethylamine in phosphate buffer $\mathrm{pH} 6.8$ and acetonitrile $(95: 5 \mathrm{v} / \mathrm{v})$ as mobile phase. The flow rate was $0.4 \mathrm{ml} / \mathrm{min}$ coupled with $5 \mu$ injection volumes and UV-detection at 238 $\mathrm{nm}$ for RIF, INH, PYR, and at $210 \mathrm{~nm}$ for EMB.

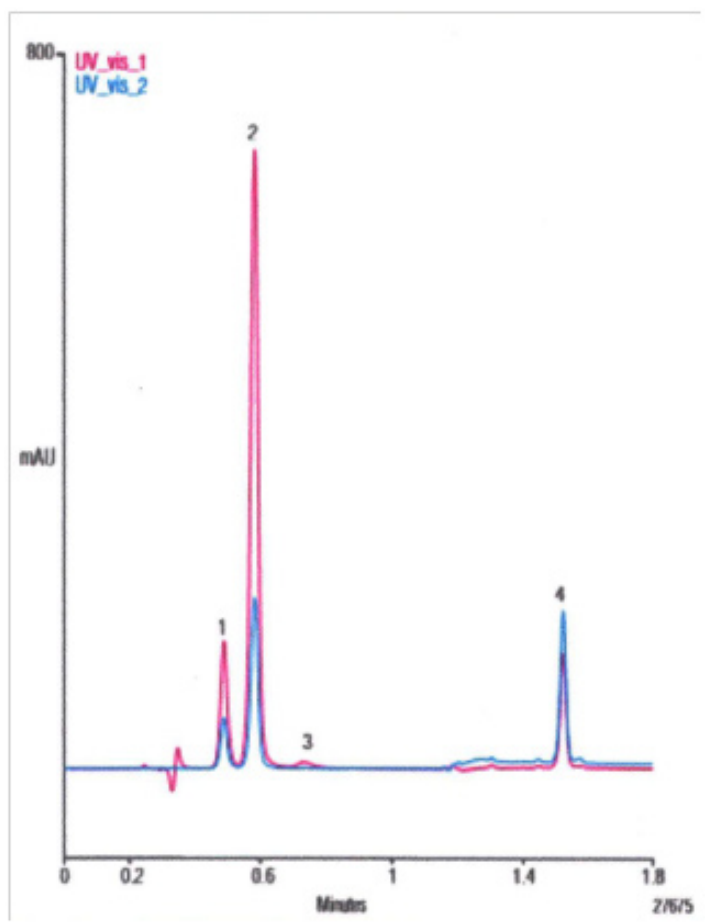

Fig. 3: Chromatogram of standard solution injected into UHPLC column (1) INH (2) PYP (3) EMB and (4) RIF

\section{Stock and working standard solutions}

A stock solution was prepared by dissolving 7.5. mg INH, $15 \mathrm{mg} \mathrm{RIF,} 22.5 \mathrm{mg}$ EMB and $40 \mathrm{mg}$ PYP in $100 \mathrm{ml}$ of mobile phase. Working standard solutions were prepared by properly diluting stock solution with the mobile phase.

\section{Method Validation}

The UHPLC method was validated as per $\mathrm{ICH}$ guidelines ${ }^{19}$ by investigating the following parameters:

\section{(a) Linearity}

This was assessed by seven-point calibration curves in triplicate. Three standard solutions were prepared as described in section 1.3. Aliquots of these standard solutions were diluted with the mobile phase to seven varying concentrations, 45-90 $\mu \mathrm{g} / \mathrm{ml}$ INH, 90-180 $\mu \mathrm{g} / \mathrm{ml}$ RIF, 65-330 $\mu \mathrm{g} / \mathrm{ml}$ EMB, and $240-480 \mu \mathrm{g} / \mathrm{ml}$ PYP. Calibration curves of the concentration versus area under peak were plotted and the data obtained were subjected to linear regression analysis employing the least-squares method.

\section{(b) Precision}

To evaluate the intraday precision, six samples at $100 \%$ of the test concentration were analyzed $(75 \mu \mathrm{g} / \mathrm{ml} \mathrm{INH}, 275 \mu \mathrm{g} / \mathrm{ml}$ EMB, $150 \mu \mathrm{g} /$ $\mathrm{ml} \mathrm{RIF,} \mathrm{and} 400 \mu \mathrm{g} / \mathrm{ml}$ PYR). Interday precision was tested on consecutive days by different analysts. Intraday $(n=6)$ and interday $(n=12)$ precision were expressed as RSD.

\section{(c) Recovery}

Standard addition in a placebo formulation (microcrystalline cellulose, PVPK30, Crospovidone, magnesium stearate) was adopted to investigate recovery. The placebo was prepared from the

Table 1: Overview of the linearity data results for INH, RIF, EMB, and PYP

\begin{tabular}{lccccc}
\hline Drug & $\begin{array}{c}\text { Number } \\
\text { of Points }\end{array}$ & $\begin{array}{c}\text { Slope } \\
\mathbf{S} \mathrm{SE}\end{array}$ & $\begin{array}{c}\text { Regression Parameters } \\
\text { Intercept } \\
\mathbf{\pm} \mathrm{SE}\end{array}$ & $\begin{array}{c}\text { Conc. Range } \\
(\boldsymbol{\mu g} / \mathbf{m l})\end{array}$ & $\begin{array}{c}\text { Regression } \\
\text { coefficient }\left(\mathbf{r}^{2}\right)\end{array}$ \\
\hline INH & 7 & $5912 \pm 16.4$ & $28260 \pm 11.2$ & $45-90$ & 0.998 \\
RIF & 7 & $5730 \pm 11.2$ & $30323 \pm 10.0$ & $90-180$ & 0.996 \\
EMB & 7 & $162.4 \pm 4.9$ & $874.1 \pm 7.4$ & $165-330$ & 0.993 \\
PYP & 7 & $4319 \pm 12.8$ & $32826 \pm 9.7$ & $240-480$ & 0.998 \\
\hline
\end{tabular}


formulation components in the absence of the active pharmaceutical ingredients.

Aliquots 20, 25, and $30 \mathrm{ml}$ of the standard stock solution (section 1.3) were added to $50 \mathrm{ml}$ volumetric flask containing $12.4 \mathrm{mg}$ placebo yielding three concentration levels (80, 100, and 120\%) relative to the theoretical concentrations of $\mathrm{RIF}$, INH, PYP and EMB. At each level, the solutions were prepared in triplicate and the recovery was calculated.

\section{(d) Specificity}

The specificity of the developed assay method was tested in relation of the placebo formulation to the standard diluted solution; both were injected into the chromatograph to discern any possible interfering peaks.

\section{(e) Robustness}

Modified parameters were evaluated individually relative to the original conditions of the analysis. The parameters varied were column temperature, mobile phase composition, and flow rate in order to test robustness.

A standard solution and three sample solutions were prepared for each parameter and injected thrice into the chromatograph. Analysis of variance (ANOVA) was utilized at a significance level of 0.05 to determine the influence of each parameter on the developed analytical method.

\section{Analysis of $\mathbf{4}$ fixed-dose combination tablets}

Twenty tablets each containing $75 \mathrm{mg}$ INH, 150 mg RIF, 275 mg EMB and 400 mg PYP were pulverized and an accurately weighed portion of the powder equivalent to about $7.5 \mathrm{mg} \mathrm{INH}$ was transferred to a beaker, followed by the addition of 50 $\mathrm{ml}$ mobile phase. The mixture was sonicated for 10 minutes, then filtered using quantitative filter paper into a $100 \mathrm{ml}$ standard flask, and finally adjusted to volume with the mobile phase.

Volumes of $5 \mu$ l taken from the prepared sample solution, were injected into the chromatograph and run at the flow rate $0.4 \mathrm{~min} / \mathrm{ml}$ and $40^{\circ} \mathrm{C}$ temperature as established in the validation step. Three batches from Sivizera Labs (SL2076, SL094, and SL2145) and two batches from Lupin Pharmaceuticals Inc. (AH28024 and AH28037) were analyzed.

\section{RESULTS AND DISCUSSION}

Figures 2a-2d depict the UV-Spectra of pure PYP, EMB, INH, and RIF in the mobile phase. The drugs exhibit substantial UV absorption in the range of $200 \mathrm{~nm}$ to $300 \mathrm{~nm}$ with the exception of EMB which shows UV absorption in the range 200 $\mathrm{nm}$ to $210 \mathrm{~nm}$.

Table 2: UHPLC precision data for INH, RIF, EMB, and PYP

\begin{tabular}{lcccc}
\hline \multirow{2}{*}{ Drug } & \multicolumn{2}{c}{ Intraday Precision $(\mathbf{n}=\mathbf{6})$} & \multicolumn{2}{c}{ Interday Precision ( $\mathbf{n}=12)$} \\
& Content (\%) & RSD (\%) & Content (\%) & RSD (\%) \\
\hline INH & 102.9 & 1.97 & 103.2 & 1.84 \\
RIF & 99.3 & 1.15 & 98.7 & 0.96 \\
EMB & 98.9 & 0.98 & 99.2 & 1.98 \\
PYP & 102.1 & 1.62 & 101.4 & 1.35 \\
\hline
\end{tabular}

Table 3: Mean content of INH, RIF, EMB, and PYP in two batches

\begin{tabular}{lcccc}
\hline \multirow{2}{*}{ Batch } & \multicolumn{4}{c}{ Content (\%) \pm RSD } \\
& INH & RIF & EMB & PYP \\
\hline Batch 1 & $102.3 \pm 1.5$ & $104.9 \pm 1.2$ & $100.2 \pm 1.6$ & $101.0 \pm 1.4$ \\
Batch 2 & $104.8 \pm 1.3$ & $103.8 \pm 1.1$ & $99.9 \pm 2.1$ & $101.4 \pm 1.7$ \\
\hline
\end{tabular}


Figure 3 shows the chromatogram obtained for the four drugs under the optimized chromatographic conditions. The retention times were $0.45 \mathrm{~min}, 0.60 \mathrm{~min}, 0.85 \mathrm{~min}$, and $1.55 \mathrm{~min}$, for INH, PYP, EMB, and RIF, respectively. Clearly, the chromatogram demonstrates $\mathrm{INH}$ to be the most polar and RIF to be the least polar.

Table 1 assembles the regression parameters from the data results obtained in the chromatographic analysis of INH, RIF, PYP, and EMB. The coefficient of determination $\left(r^{2}\right)$ is close to unity suggesting adequate linearity.

Table 2 summarizes the content $\%$ and RSD of INH, RIF, EMB, and PYP. All results indicate satisfactory precision of less than $2 \%$ RSD compliance of the contents with the specifications.

Table 3 summarizes the mean content \% \pm RSD of INH, RIF, EMB, and PYP in two batches.

The HPLC method for the simultaneous determination of INH, RIF, EMB and PYP poses a challenge; firstly due to the pronounced differences in the polarity of these drugs and secondly due to the poor UV absorption of EMB in the longer wavelength UV range. The aim of this work was to create a single method to determine INH, RIF, EMB and PYP in the combination drug product. The USP34 monograph has two HPLC methods for the determination of INH, RIF, and PYP using sodium phosphate buffer $\mathrm{pH} 6.8$ and acetonitrile as eluent and detection at $238 \mathrm{~nm}$ wavelength. The second method for the quantification of EMB, involves the use of triethylamine $\mathrm{pH} 7$ and acetonitrile as eluent with detection at $200 \mathrm{~nm}$ wavelength. Previously, these challenges were overcome by additional steps of pre-column derivatization utilizing phenethyl isocyanate ${ }^{20}$ or complexation of EMB with Cu (II) to form UV-absorbing product ${ }^{21}$. The three approaches, namely, the complexation of EMB with $\mathrm{Cu}(\mathrm{II})$, the precolumn derivatization with phenethyl isocyanate, and the two assay methods adopted by USP are laborious and time consuming.
To create a single method in this investigation of the four anti-tubercular drugs, UHPLC technique was used with triethylamine in sodium phosphate buffer $\mathrm{pH} 6.8$ and acetonitrile as eluent. Adequate results were obtained at $238 \mathrm{~nm}$ detection for $\mathrm{INH}$, RIF, and PYP. Regarding EMB, optimum results were observed at $210 \mathrm{~nm}$ where a stable base-line and satisfactory sensitivity were realized. This dual wavelength approach eliminated the complexation and the derivation procedures pointed out previously. Unlike the conventional HPLC where $5 \mu \mathrm{m}$ particle size is usually used, the tightly packed column with $1.7 \mu \mathrm{m}$ particle size employed in the UHPLC technique yielded satisfactory resolution and sharp peaks free from tailing. Furthermore, the total run time was considerably less than 2 min (Figure 3 ). This is a dramatic reduction in the chromatographic run time, which facilitates the analysis of drug samples in busy quality control laboratories.

\section{CONCLUSION}

The developed method investigated in this endeavor showed that the UHPLC technique improved substantially the speed, sensitivity, and peak resolution. The total run time for the assay of the 4 anti-tubercular drugs in the reported HPLC methods was long compared to less than 2 min in the UHPLC technique (Figure 3). It may be concluded that the ability of the developed method to quantify simultaneously the 4 drugs in less than 2 minutes makes it superior to the HPLC and the other reported methods. In addition, the developed method possesses adequate precision, accuracy, and selectivity and is therefore eligible to be adopted in quality control laboratories for the simultaneous determination of INH, RIF, PYP and EMB in tablets.

\section{ACKNOWLEDGMENTS}

The authors wish to acknowledge the approval and the support of this research study by the grant Number 3-12-1436-5 from the Deanship of the Scientific Research in Northern Border University (N.B.U.), Arar, KSA. 


\section{REFERENCES}

1. Sulis G., Roggi A., Matteelli A., Raviglione M.C., Mediterr. J. Hematol. Infect. Dis. 2014, 6(1), e2014070.

2. Carvalho S.A., Da Silva E.F., De Souza M.V.N., Lourenco M.C.S., Vicente F.R., Bioorg. Med. Chem. Lett. 2008, 18(2), 538541.

3. World Health Organization, An Expanded DOTS framework for effective Tuberculosis control (WHO/CDS/TB/2002), 2002 (Available online at http://apps.who.int/iris/ bitstream/10665/67232/1/WHO_CDS_ TB_2002.297.pdf).

4. Wu W.Y., Yang J.Y., Du L.M., Wu H., Li C.F., Spectrochim Acta A Mol. Biomol. Spectrosc. 2011, 79(3), 418-422.

5. Hammam E., Beltagi A.M., Ghoneim M.M., Microchemical J. 2004, 77(1), 53-62.

6. De Souza M.V., Fitoterapia, 2009, 80(8), 453460.

7. Benettlon S.A., Kedor-Hackmann E.R.M., Santoro M.I.R.M., Borges M.V., Talanta, 1998, 47(3), 639-643.

8. Goicoechea H.C., Olivieri A.C., J. Pharm. Biomed. Anal. 1999, 20(4), 681-686.

9. Espinosa-Mansila A., Valenzuela M.I.A., De la Pena A.M., Salinas F., Canada F.C., Anal. Chim. Acta, 2001, 427(1), 129-136.

10. Madan J., Dwivedi A.K., Singh S., Anal. Chim. Acta, 2005, 538(1-2), 345-353.

11. Songh S.H., Jun S.H., Park K.U., Yoon Y., Lee
J.H., Kim J.Q., Song J., Rapid Commun. Mass Spectrom. 2007, 21(7), 1331-1338.

12. Farla A.F., De Souza M.V., Bruns R.E., De Oliveira M.A., Talanta, 2010, 82(1), 333339.

13. Calleri E., De Lorenzi E., Furlanetto S., Massolini G., Caccialanza G., J. Pharm. Biomed. Anal. 2002, 29(6), 1089-1096.

14. Khuhawar M.Y., Rind F.M., J. Chromatogr. B Analyt. Technol. Biomed. Life Sci. 2002, 766(2), 357-363.

15. Breda M., Marrari P., Pianezzola E., Benedetti S.M., J. Chromatogr. A, 1996, 729(1-2), 301307.

16. Jiang Z., Wang H., Locke D.C., Anal. Chim. Acta, 2002, 456(2), 189-192.

17. Shewiyo D.H., Kaale E., Risha P.G., Dejaegher B., Smeyers-Verbeke J., Heyden Y.V., J. Chromatogr. A, 2012, 1260, 232-238.

18. Thapliyal N., Karpoormath R.V., Goyal R.N., Anal. Chim. Acta, 2015, 853, 59-76.

19. International Conference on Hormonization, Draft Guidelines on Validation of Analytical Procedures: Definition of Technology, Federal Register, 1995, 60, 11260.

20. Wang H., Cai C., Chu C., Liu J., Kong Y., Zhu M., Zhang T., Asian J. Pharm. Sci. 2012, 7(4), 303-309.

21. Faria A.F., de Souza M.V.N., Bruns R.E., de Oliveira M.A.L., J. Chromatogr. A. 2008, 1202(2), 224-228. 